\title{
A preliminary study on the potential of front face fluorescence spec- troscopy for Italian mono-cultivar extra virgin olive oil discrimination
}

\author{
Dimas Firmanda Al Riza, ${ }^{1,2}$ Naoshi Kondo, ${ }^{1}$ Pasquale Catalano, ${ }^{3}$ Ferruccio Giametta ${ }^{1,3}$ \\ ${ }^{1}$ Laboratory of Biosensing Engineering, Graduate School of Agriculture, Kyoto University, Kyoto, Japan; \\ ${ }^{2}$ Department of Agricultural Engineering, Faculty of Agricultural Technology, University of Brawijaya, Malang, \\ Indonesia; ${ }^{3}$ Department of Agriculture, Environment, and Food, University of Molise, Campobasso, Italy
}

\begin{abstract}
Front-face fluorescence method has been used to obtain fluorescence excitation emission matrix (EEM) characteristic of various Italian monocultivar extra virgin olive oil (EVOO), Mixed EVOO, and lower grade virgin olive oil. Specific region of EEM has been explored using principle component analysis. It was found that EEM region of excitation 250-400 and emission 280$620 \mathrm{~nm}$ could be used to discriminate each sample type of different cultivar, mixed sample, and virgin olive oil sample. The important fluorescence peaks for the discrimination belong to unique combination of tocopherols, tocotrienols, phenolic compounds, oxidation products, and vitamin E. These results show that frontface fluorescence EEM spectroscopy has a potential to be used for monocultivar EVOO discrimination.
\end{abstract}

\section{Introduction}

Extra virgin olive oil (EVOO) is a high-quality vegetable oil obtained from the first cold mechanical press of the olive fruits (Olea europaea L.). The EVOO does not undergone further processing that leads to the alterations of the original properties (Vila, 2005). There are many varieties of olive tree cultivar, which will produce EVOO with unique physical and sensory characteristics. The demand for traced monovarietal EVOO is growing since the customer expecting the high-quality unique flavor and health benefit, avoiding also that such olives could be mixed with non-traced

Correspondence: Ferruccio Giametta, Department of Agriculture, Environment, and Food, University of Molise, via Francesco De Sanctis, 86100 Campobasso, Italy.

E-mail: ferruccio.giametta@unimol.it

Key words: Spectroscopy; fluorescence; olive oil; optical properties; monocultivar.

Acknowledgements: the first author is grateful to LPDP - Ministry of Finance Indonesia Republic for the financial support during the study.

Received for publication: 29 May 2018

Accepted for publication: 31 July 2018.

(C) Copyright D.F. Al Riza et al., 2018

Licensee PAGEPress, Italy

Journal of Agricultural Engineering 2019; L:877

doi:10.4081/jae.2018.877

This article is distributed under the terms of the Creative Commons Attribution Noncommercial License (by-nc 4.0) which permits any noncommercial use, distribution, and reproduction in any medium, provided the original author(s) and source are credited. olives or with different features (acidity, number of peroxides, etc.).

World and Italian olive oil consumption increased respectively by $79 \%$ and $8 \%$ during last 25 years while, in Japan, 2016 consumption of 66,139 tons represented a $1400 \%$ increase over the same period (Italian farmers Group, Coldiretti, 2016). In Italy, there are more than 800 cultivars of indigenous Italian olive germplasm (Rotondi et al., 2013) and 43 origins protected by the European Union. Knowledge and development of the characteristics of Italian monovarietal EVOO is important for the improvement of olive oil industry and tourism, which is crucial sector for Italian economy. The concept of quality of the EVOO has evolved over time. In fact, while in the past, product quality weighed heavily on consumer choices, today the trend prevails to direct purchases towards extra virgin oils with a clear organoleptic identity and a good supply of compounds with antioxidant activity, such as biophenols and tocopherols. The volatile compounds responsible for the olfactory notes of the oil are formed along the path of lipoxygenase during technological transformation at the mill (Tamborrino et al., 2017; Caponio et al., 2018). From a sensory point of view, biophenols are mostly perceived as spicy and bitter notes which are directly related to the health action (Servili et al., 2004). As is well known, the cultivar greatly influences sensory and analytical characteristics of olive oil. Among environmental factors, soil water availability during fruit development, light, and temperature are mainly responsible for changes in fatty acids composition and biophenolic concentrations. Irrigation, date of harvesting and alternate bearing also influences olive oil quality, whereas the effect of soil management, pruning or fertilisation is less clear. Fruit damage due to incorrect harvesting methods, transport to oil mill, storing or pests greatly decreases olive oil phenolic concentrations and increases free acidity and peroxide value (Gucci et al., 2004).

The degree of ripeness of the fruit at the time of harvesting has a major influence on its quality, and everything that alters the ripeness of the fruit also affects its quality. Oil obtained from fruit at an advanced stage of ripening usually has lower concentrations of phenolic and volatile compounds than oils extracted from olives with a skin that is not completely pigmented. As ripening progresses, there are also variations in the acid composition with a tendency to increase the ratio between unsaturated and saturated acids. Olive oil acidity level is given by the amount of free fatty acids resulting from the hydrolytic degradation of triglycerides. Therefore, the chemical analysis carried out to assess the acidity level of olive oil allows for one first assessment of a parameter which is also a crucial indicator of the quality of the product (Giametta and Sciarrone, 2008). As far as the harvesting method is concerned, oils of the highest quality can be produced from both manual and mechanical harvesting, provided that the minimum precautions are taken to avoid damage to the fruit and that processing in the mill is carried out in short time (Gucci et al., 2004; Servili et al., 2004; Inglese et al., 2011). 
In the light of the above, there have been considerable amount of efforts for Italian Olive Oil discrimination by using various method i.e. nuclear magnetic resonance, chemical composition analysis, infrared spectroscopy (Shaw et al., 1997; Bucci et al., 2002; Sinelli et al., 2010). Most of those methods are laborious and relatively expensive but they represent quite good discrimination techniques. Fluorescence technique is known to be an emerging method for food analysis and has been developed very well in the last two decades (Christensen et al., 2006). This method has a high sensitivity, relatively cheaper, and easy to be used. This method is based on a fluorescence phenomenon, which is emission of light from singlet-excited states. The emitted light wavelength usually longer than the excitation wavelength (Lakowicz, 2006). Fluorescence spectroscopy measurement could be carried out by using either right angle method for diluted sample or front face method for high concentrated or solid sample. Among fluorescence measurement techniques front face method is very promising for the ability in measure intact sample with less pre-treatment and less effect of other optical phenomenon such as inner filter effect.

Guimet et al. (2005) revealed that fluorescence excitation emission matrix (EEM) combined with three ways method could be used for olive oil grade characterisation. The fluorescence spectra has been also used to characterise the overall quality of olive oil especially based on the oxidised state represented by some fluorescence peaks (Guzmán et al., 2015). Recently, Leo et al. (2016) found that 3D fluorescence spectroscopy combined with principle component analysis (PCA) could be used to classify EVOO and virgin olive oil (VOO), the spectra information used in this study represent a freshness due to antioxidant compound, chlorophyll and oxidation stage due to presence of oxidation products. However, the potential of fluorescence spectroscopy to be used as a fingerprint of monocultivar EVOO has not been explored yet.

This research's objective is to investigate the potential of fluorescence spectroscopy for discrimination of Italian monocultivar EVOO. Front-face fluorescence measurement method will be used to obtain the EEM and PCA will be used to explore the data further. The results of the study will give an insight to the potential of specific fluorescence EEM region to be used as a signature for monocultivar EVOO. The oil extracted were analysed to cluster the lots into classes, one for each cultivar. This allows also the detection of possible mismatches, i.e. handling or registration errors.

\section{Materials and methods}

\section{Olive oil samples}

Nine different samples of Italian olive oil were collected with the same production year and obtained in October 2016. The samples consist of six different mono-cultivars EVOO, two-mixed cultivar EVOO, and a VOO (Table 1).

\section{Fluorescence excitation emission matrix measurement and pre-processing}

The samples were put in a $10 \mathrm{~mm}$ quartz cuvette. The fluorescence EEM were acquired using Jasco FP-8300 spectrofluorometer. The measurement method was front face method by using FDA-808 Holder, which maintain the incident beam angle of about $30^{\circ}$ to the normal of the surface. Front face fluorescence measurement method is usually used for the characterisation of the solid sample or highly concentrated (undiluted) liquid surface properties. By using this method, the highly concentrated sample does not need to be diluted to avoid strong absorption and inner filter effect that could be commonly occurs in the right-angle method. The measurement range of EEM was 230-680 nm with $10 \mathrm{~nm}$ interval for excitation and 250-700 with $5 \mathrm{~nm}$ interval for emission. The distilled water Raman peak data was taken prior to fluorescence EEM measurement at $350 \mathrm{~nm}$ Excitation wavelength. The raw EEM measurement data in Arbitrary Unit (A.U.) is corrected and then converted to Raman Unit (R.U.) following the method described in Lawaetz and Stedmon (2009). This R.U. conversion was carried out to normalised measurement using different sensitivity setting and minimise the effect of device change (Figure 1).

\section{Principle component analysis}

Even though chlorophyll information could be used as an indicator of a good quality olive oil, EVOO adulteration could be easily done by putting chlorophyll in the lower grade olive oil. Furthermore, olive oil with high amount of chlorophyll could be easily observed by the green colour of the oil in the visible light. In the fluorescence EEM, chlorophyll peaks present in the emission wavelength around 648-673 $\mathrm{nm}$ with wide range of Excitation wavelength, which could be separated with other fluorescence peaks. Therefore, for further analysis we selected the region other than chlorophyll as shown in Figure 2. The region of the EEM to be used is between excitation (Ex.) 250-400 nm and emission (Em.) $280-680 \mathrm{~nm}$.

Table 1. Olive oil sample, their origin.

\begin{tabular}{llcc} 
No. & Sample & Origin & Source \\
1. & EVOO cv. Monte Etna & Sicily & Market \\
2. & EVOO cv. Chieti & Abruzzo & Market \\
\hline 3. & EVOO cv. Bosana & Sardinia & Market \\
4. & EVOO cv. Ogliarola & Apulia & Milling (Oleificio Cooperativo Bitonto) \\
\hline 5. & EVOO cv. Coratina & Apulia & Milling (Oleificio Cooperativo Bitonto) \\
6. & EVOO cv. Taggiasca & Liguria & Market \\
\hline 7. & Mix EVOO Coratina-Ogliarola-Signora & Apulia & Market \\
\hline 8. & Mix of unknown cultivar & Unknow & Market \\
\hline 9. & Virgin olive oil & Unknow & Market \\
\hline
\end{tabular}

EVOO, extra-virgin olive oil. 


\section{Excitation}

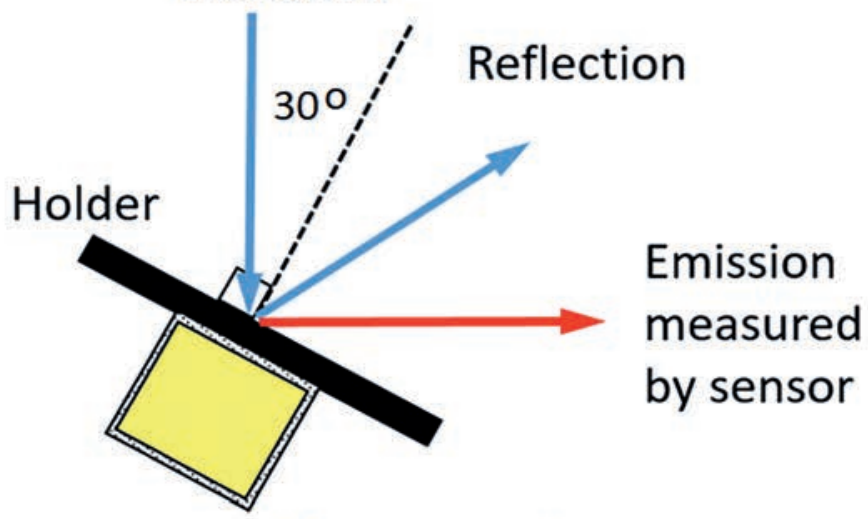

$10 \mathrm{~mm}$ cuvette
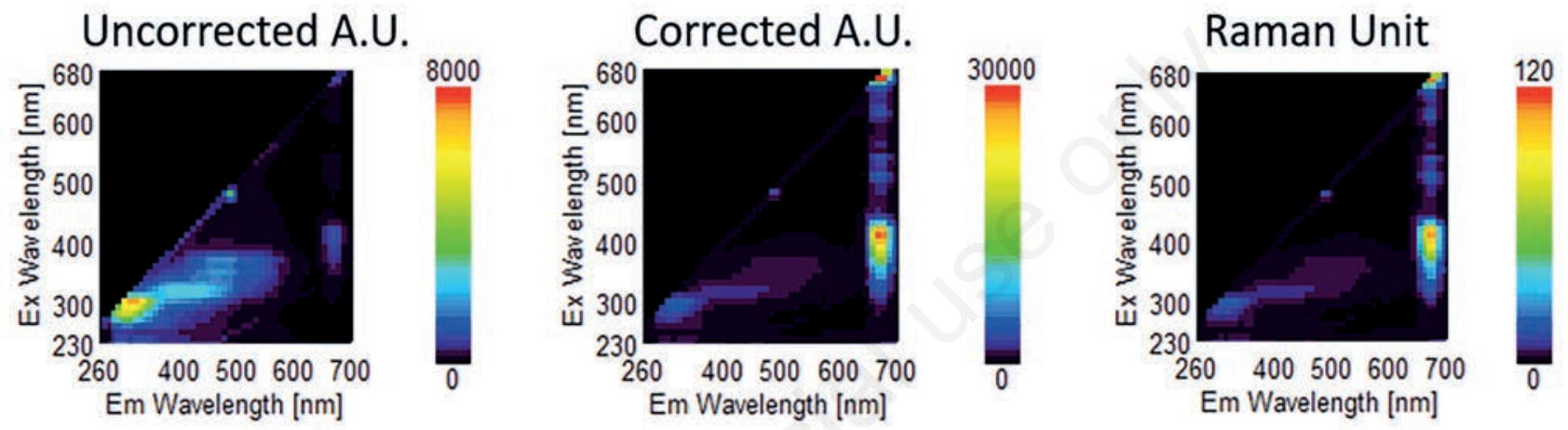

Figure 1. Front face measurement method (top) and data pre-processing (bottom). Ex, exitation; Em, emission.
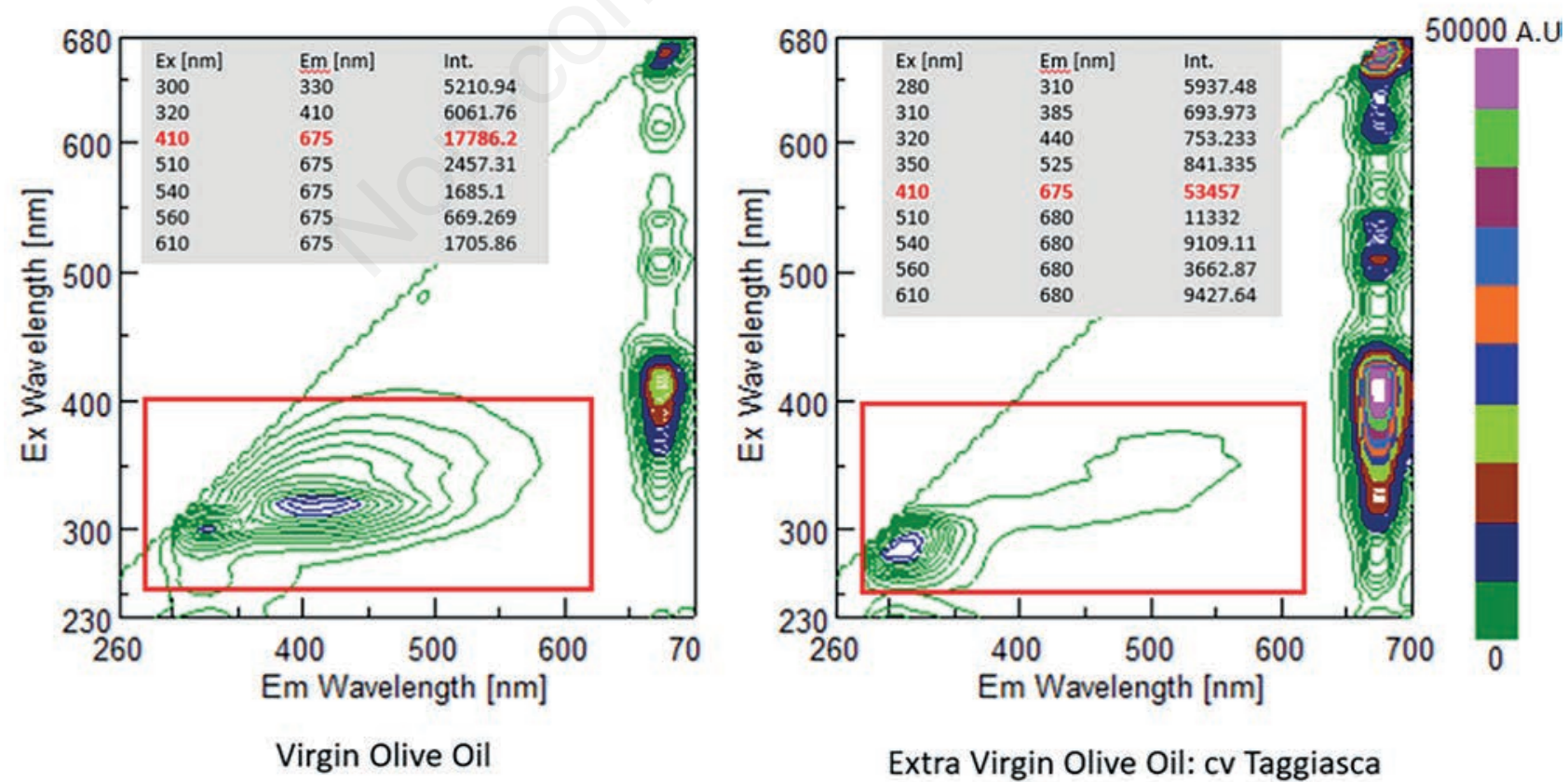

Extra Virgin Olive Oil: cv Taggiasca

Figure 2. Excitation emission matrix region of raw full range spectra to be used for principle component analysis (PCA). Ex, exitation; Em, emission. 
The 3D EEM data for each sample were unfolded and concatenated to be a one-vector data type (Figure 3). PCA was then carried out using Unscrambler ${ }^{\circledR}$ version 9.8 (CAMO, Oslo, Norway).

\section{Results and discussion}

\section{Fluorescence excitation emission matrix features of olive oils}

Chemical compositions of olive oils including the fluorescence substances are affected by factors such as type of cultivars, environmental conditions, orchard management, and extraction technologies (Inglese et al., 2011). These factors integrally will form the chemical fingerprint or characteristics of each olive oil products. Spectroscopy methods including absorbance and fluorescence method then could be used to figure out these characteristics. In case of fluorescence spectroscopy, most of the fluorophore have a characteristic in ultraviolet (UV) and visible (Vis) region. Absorption in the UV-Vis region of electromagnetic radiation is related with electron excitations. All molecules will undergo electronic excitation when absorb light, especially with high radiation energy in UV region (Nielsen, 2003). The fluorescence EEM shows the excitation emission wavelength pair and intensity related to the fluorescence substances (fluorophore).

EVOO contain several kind of fluorophore including Tocopherols and Tocotrienols which have excitation wavelength around 290-297 nm and emission around 320-324, Phenolic compound (Oleuropein, Vanilic acid, Syringic acid, Gallic acid, Coumaric acid, Cinnamic acid, Tyrosol, Caffeic acid with Excitation around 270 and Emission ranged from 310 to $457 \mathrm{~nm}$ (Sikorska et al., 2012). It can be seen at the low left part of the
EEM (Figure 4), the shape of the peaks is different between each sample EEM. It is because composition of the vitamin $\mathrm{E}$ and phenolic compounds is different for each sample. It can be noticed also that Virgin Olive Oil have lower content of phenolic compounds compared to other samples.

Other peaks located in the middle part of the EEM with emission around 400-450 nm correlated to hydro peroxide content, oxidation products, or hydrolysis products of oil which generated during malaxing (Sikorska et al., 2012; Lleó et al., 2016). It is revealed that VOO have the highest intensity peak in this region since it is undergone heating process during production while EVOO, which is produced by cold mechanical press, should have lower intensity fluorescence peak in this region.

The last region with excitation above $330 \mathrm{~nm}$ and emission between 425-600 nm suspected to correlate with vitamin E content (Kyriakidis and Skarkalis, 2000). There could be also other fluorophore contribute to the shape of the oil EEM. However, the unique combination of those fluorescence peaks could become a fingerprint in the discrimination of monocultivar EVOO.

\section{Principle component analysis and important variable for discrimination}

From the PCA score scatter plot (Figure 5) the discrimination for each sample can be seen from the spreading of the sample. It was found that 4 principle components (PC) are enough to represent $99 \%$ of samples variance. Consecutively PC-1 to PC-4 contribute to 90, 6,2 , and $1 \%$ of the variance. It can be seen that each category could be clearly separated; clustering of different cultivars is very evident and such that other parameters (irrigation, harvesting, processing, etc.) do not influence the ability of the method to discriminate between different cultivars. This is certainly a good start and further research will be carried out to assess other aspects in more detail.

\begin{tabular}{|c|c|c|c|c|c|c|c|c|c|c|c|c|c|c|c|c|c|c|c|c|c|}
\hline \multicolumn{4}{|c|}{$I I^{1} I^{1}$} & \multirow{2}{*}{\multicolumn{2}{|c|}{ S1 }} & \multirow[b]{2}{*}{$1-1$} & \multirow[b]{2}{*}{$1-2$} & \multirow[b]{2}{*}{$1-3$} & \multirow[b]{2}{*}{$1-4$} & \multirow[b]{2}{*}{$2-1$} & \multirow[b]{2}{*}{$2-2$} & \multirow[b]{2}{*}{$2-3$} & \multirow[b]{2}{*}{$2-4$} & \multirow[b]{2}{*}{$3-1$} & \multirow[b]{2}{*}{$3-2$} & \multirow[b]{2}{*}{$3-3$} & \multirow[b]{2}{*}{$3-4$} & \multirow[b]{2}{*}{$4-1$} & \multirow[b]{2}{*}{$4-2$} & \multirow[b]{2}{*}{$4-3$} & \multirow[b]{2}{*}{$4-4$} \\
\hline $1-1$ & $1-2$ & $1-3$ & $1-4$ & & & & & & & & & & & & & & & & & & \\
\hline $2-1$ & $2-2$ & $2-3$ & $2-4$ & \multirow{3}{*}{ s3 } & \multirow[b]{2}{*}{ S2 } & \multirow[b]{2}{*}{$1-1$} & \multirow[b]{2}{*}{$1-2$} & \multirow[b]{2}{*}{$1-3$} & \multirow[b]{2}{*}{ 1-4 } & \multirow[b]{2}{*}{$2-1$} & \multirow[b]{2}{*}{$2-2$} & \multirow[b]{2}{*}{$2-3$} & \multirow[b]{2}{*}{$2-4$} & \multirow[b]{2}{*}{$3-1$} & \multirow[b]{2}{*}{$3-2$} & \multirow[b]{2}{*}{$3-3$} & & & & & \\
\hline 3-1 & 3-2 & $3-3$ & $3-4$ & & & & & & & & & & & & & & \multicolumn{2}{|r|}{$4-1$} & $4-2$ & $4-3$ & $4-4$ \\
\hline $4-1$ & & & 4-4 & & S3 & $1-1$ & $1-2$ & $1-3$ & $1-4$ & $2-1$ & $2-2$ & $2-3$ & $2-4$ & $3-1$ & $3-2$ & $3-3$ & 3-4 & $4-1$ & $4-2$ & $4-3$ & $4-4$ \\
\hline & & & & & $\ldots$ & $1-1$ & $1-2$ & $1-3$ & $1-4$ & $2-1$ & $2-2$ & $2-3$ & $2-4$ & $3-1$ & $3-2$ & $3-3$ & $3-4$ & $4-1$ & $4-2$ & $4-3$ & $4-4$ \\
\hline
\end{tabular}

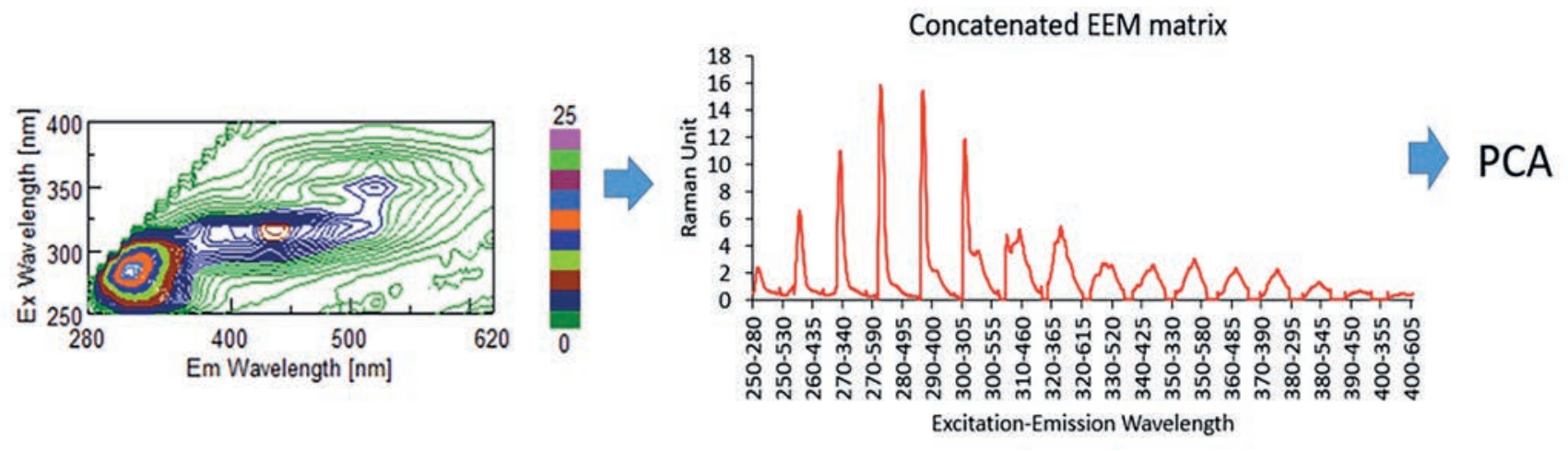

Figure 3. Conversion of 3D excitation emission matrix (EEM) data to concatenated EEM matrix for principle component analysis (PCA). Ex, exitation; Em, emission. 


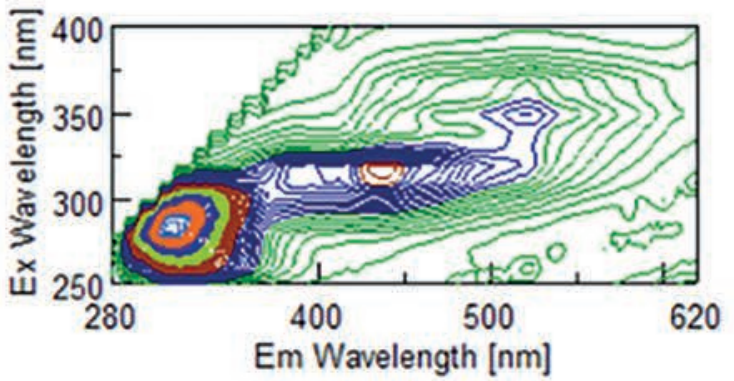

A. Monte Etna

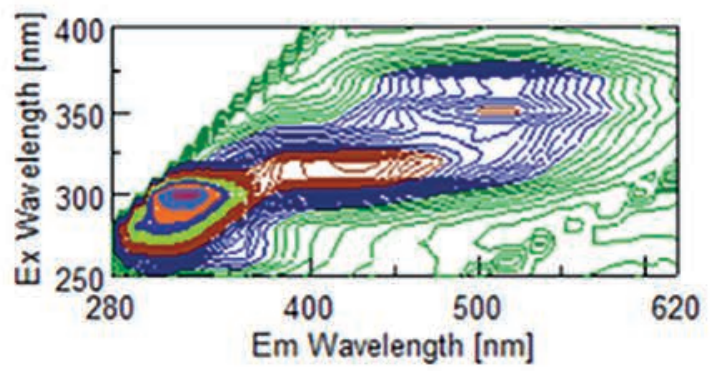

C. Bosana

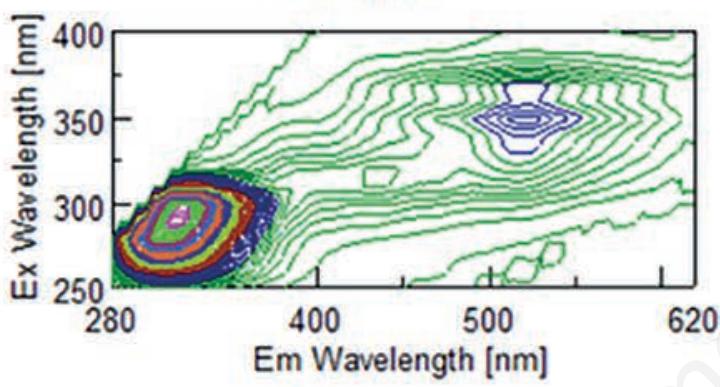

E. Coratina

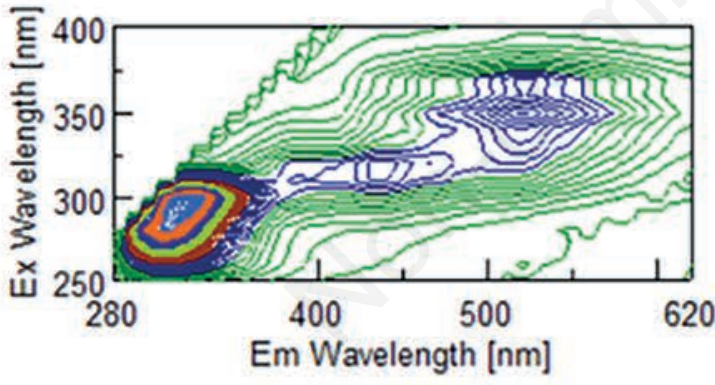

G. Mix - Coratina-Ogliarola-Signora

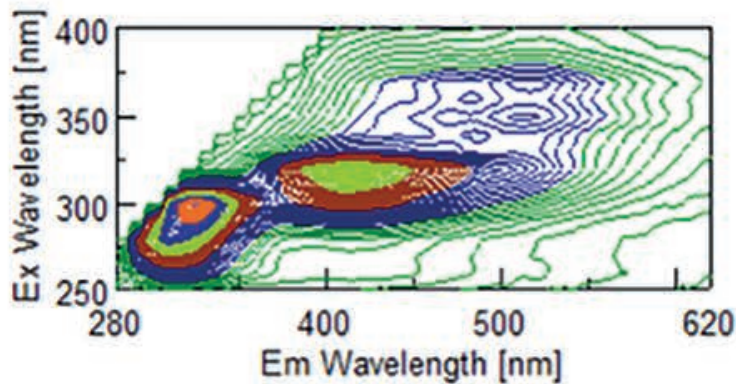

B. Chieti

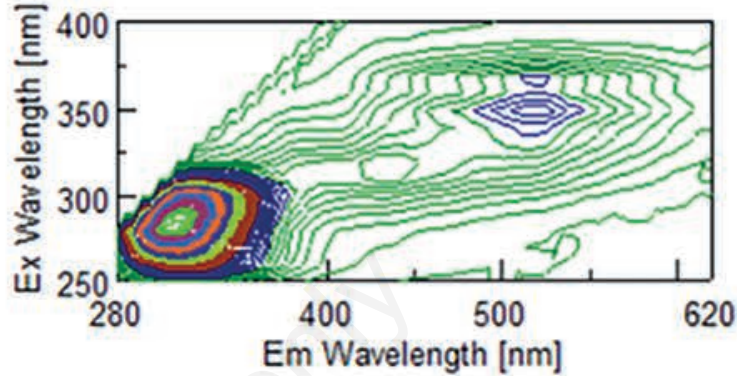

D. Ogliarola

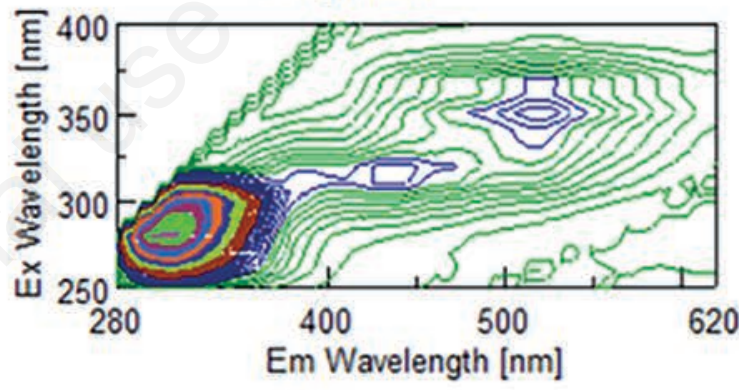

F. Taggiasca

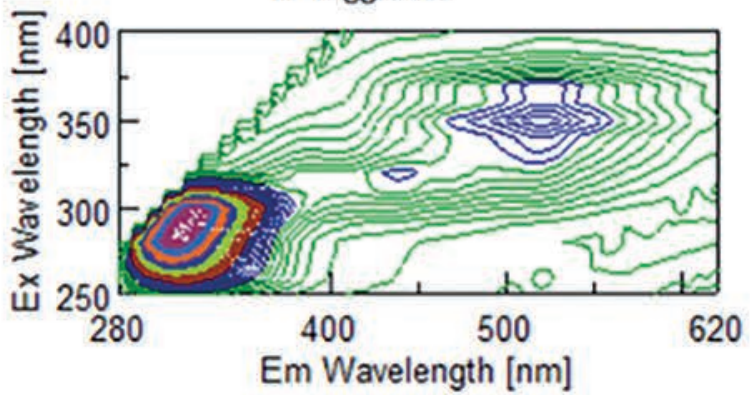

H. Unknown - Unfiltered EVOO

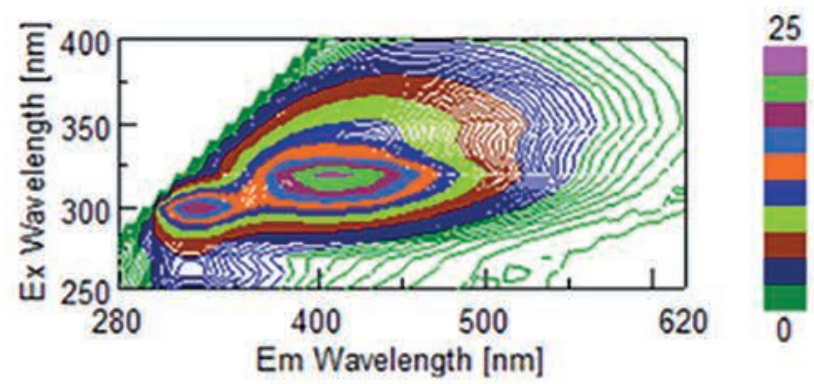

Raman Unit (R.U.)

I. Virgin Olive Öil

Figure 4. Representative fluorescence excitation emission matrix for each sample. Ex, exitation; Em, emission; EVOO, extra-virgin olive oil. 
This can be useful: i) at the end of the extraction process in order to identify the different production lots (i.e. from different cultivars) and trace them correctly; ii) during distribution and sale phases in order to trace the origin of lots non-conforming with the label. Figure 6 shows the 3D correlation-loading plot of PC-1 to 4 . In PC-1, which represents $90 \%$ variety of the sample, we can see that almost all wavelength contributed to the discrimination.
Emission region between 360-600 nm contributed positively while Emission region of 280-360 nm show negative correlation loading value. PC-2 shows the most important fluorescence peaks belong to Tocopherols, Tocotrienols (Ex./Em. 290/320 nm) and Phenolic compounds (Ex./Em. 270/350 nm) that is contributed to the discrimination. PC-3 discrimination mostly affected by emission Region more than $520 \mathrm{~nm}$ and small part of Tocopherols and

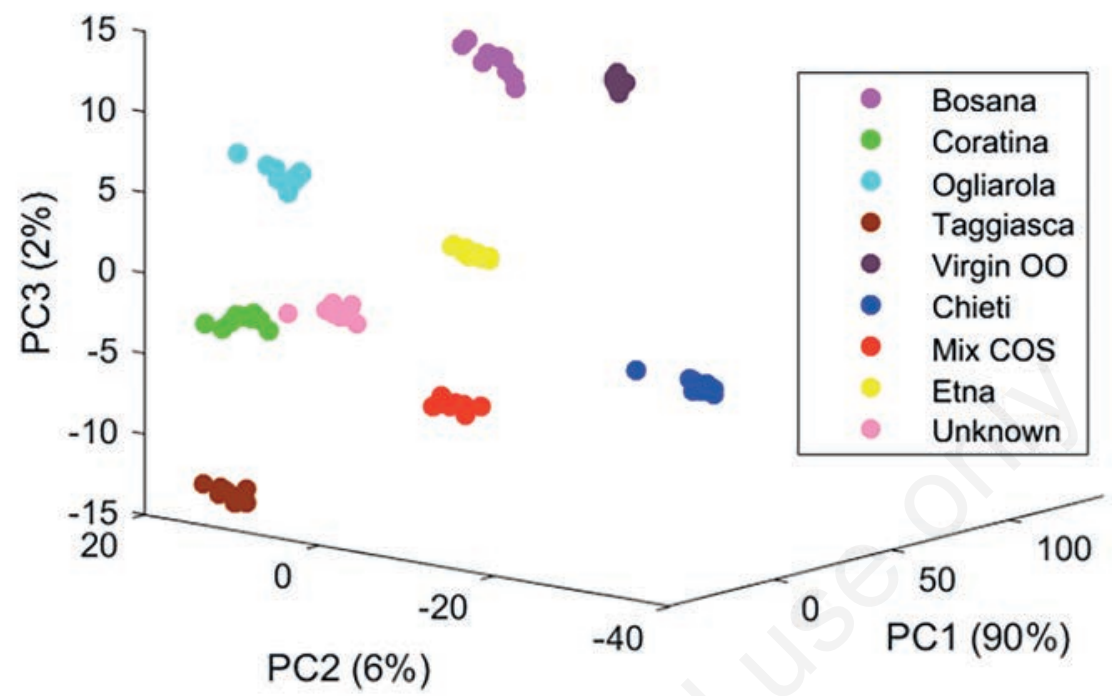

Figure 5. Principle component (PC) analysis scores plot for all wavelengths. OO, olive oil; COS, Coratina-Ogliarola-Signora.
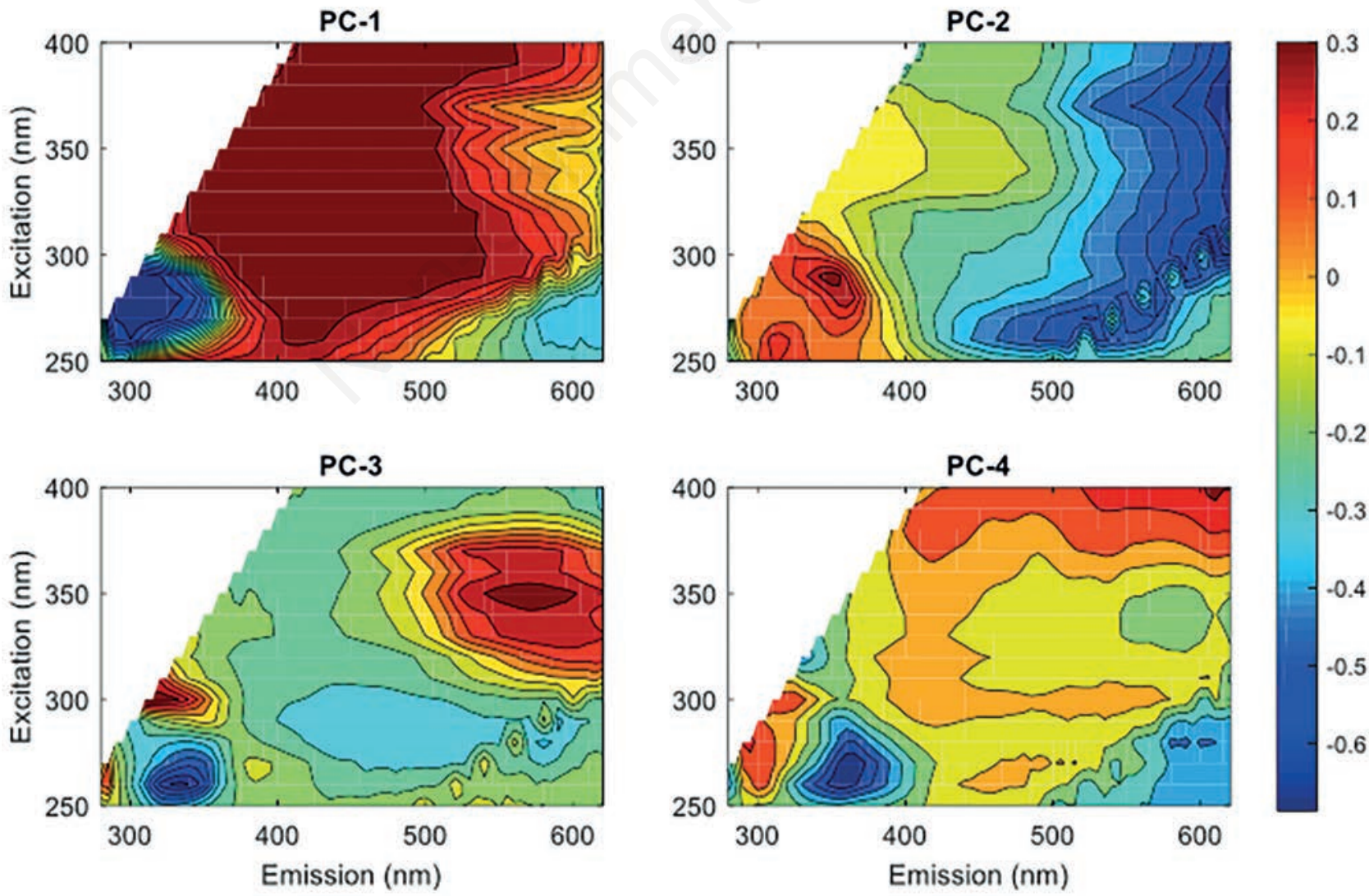

Figure 6. Colour map plot of loading for each principal component for all wavelengths. PC, principle component. 
Tocotrienols peaks. Since PC-1 to 3 has already represent $98 \%$ of the discrimination PC-4 includes less important information for the discrimination.

\section{Conclusions}

Front-face fluorescence method has been used to obtain EEM characteristic of various Italian monocultivar EVOO. Specific region of EEM, which is, belong to Tocopherols, Tocotrienols, phenolic compounds, oxidation products, and vitamin E. It was found that EEM region of Ex. 250-400 and Em. 280-620 could be used to discriminate each sample type of different cultivar, mixed sample, and virgin olive oil sample. These results demonstrated the potential of front-face fluorescence spectroscopy for discrimination of monocultivar EVOO.

\section{References}

Bucci R., Magrí A.D., Magrí A.L., Marini D., Marini F. 2002. Chemical authentication of extra virgin olive oil varieties by supervised chemometric procedures. J. Agric. Food Chem. 50:413-8.

Caponio F., Squeo G., Brunetti L., Pasqualone A., Summo C., Paradiso V.M., Catalano P., Bianchi B. 2018. Influence of the feed pipe position of an industrial scale two-phase decanter on extraction efficiency and chemical-sensory characteristics of virgin olive oil: Decanter feeding impact on extraction efficiency and olive oil quality. J. Sci. Food Agric. 98:4279-86.

Christensen J., Nørgaard L., Bro R., Engelsen S.B. 2006. Multivariate autofluorescence of intact food systems. Chem. Rev. 106:1979-94.

Giametta F., Sciarrone G. 2008. An integrated technological traceability model in the olive growing production chain. J. Agric. Eng. 39:19.

Gucci R., Servili M., Esposto S., Selvaggini R. 2004. Oil quality of olive cv. 'Leccino' grown under irrigated or dry-farmed conditions. Acta Hortic. 297-302.

Guimet F., Ferré J., Boqué R., Vidal M., Garcia J. 2005. Excitationemission fluorescence spectroscopy combined with three-way methods of analysis as a complementary technique for olive oil characterization. J. Agric. Food Chem. 53:9319-28.

Guzmán E., Baeten V., Pierna J.A.F., García-Mesa J.A. 2015. Evaluation of the overall quality of olive oil using fluorescence spectroscopy. Food Chem. 173:927-34.

Inglese P., Famiani F., Galvano F., Servili M., Esposto S., Urbani S. 2011. Factors affecting extra-virgin olive oil composition.
Horticult. Rev. 83-147.

Kyriakidis N.B., Skarkalis P. 2000. Fluorescence spectra measurement of olive oil and other vegetable oils. J. AOAC Int. 83:1435-9.

Lakowicz J.R. 2006. Principles of fluorescence spectroscopy, 3rd ed. Springer, USA.

Lawaetz A.J., Stedmon C.A. 2009. Fluorescence intensity calibration using the Raman scatter peak of water. Appl. Spectrosc. 63:936-40.

Lleó L., Hernández-Sánchez N., Ammari F., Roger J.-M. 2016. 3D front-face fluorescence spectroscopy for characterization of extra virgin olive oil and olive oil according to the spectral pattern. Agric. Eng. Int. CIGR J. 18:190.

Nielsen S.S. (Ed.). 2003. Food analysis, 3. ed. ed, Food science text series. Kluwer Academic, Plenum Publishers, New York, NY, USA.

Rotondi A., Magli M., Morrone L., Alfei B., Pannelli G. 2013. Italian National database of monovarietal extra virgin olive oils. Available from: https://doi.org/10.5772/51772

Servili M., Selvaggini R., Esposto S., Taticchi A., Montedoro G., Morozzi G. 2004. Health and sensory properties of virgin olive oil hydrophilic phenols: agronomic and technological aspects of production that affect their occurrence in the oil. J. Chromatogr. A 1054:113-27.

Shaw A.D., di Camillo A., Vlahov G., Jones A., Bianchi G., Rowland J., Kell D.B. 1997. Discrimination of the variety and region of origin of extra virgin olive oils using 13C NMR and multivariate calibration with variable reduction. Anal. Chim. Acta 348:357-74.

Sikorska E., Khmelinskii I., Sikorski M. 2012. Analysis of olive oils by fluorescence spectroscopy: methods and applications. Available from: https://doi.org/10.5772/30676

Sinelli N., Cerretani L., Egidio V.D., Bendini A., Casiraghi E. 2010. Application of near (NIR) infrared and mid (MIR) infrared spectroscopy as a rapid tool to classify extra virgin olive oil on the basis of fruity attribute intensity. Food Res. Int. 43:369-75.

Tamborrino A., Squeo G., Leone A., Paradiso V.M., Romaniello R., Summo C., Pasqualone A., Catalano P., Bianchi B., Caponio F. 2017. Industrial trials on coadjuvants in olive oil extraction process: effect on rheological properties, energy consumption, oil yield and olive oil characteristics. J. Food Eng. 205:34-46.

Vila F.G. 2005. Olive oil characterization using excitation-emission fluorescence spectroscopy and three-way methods of analysis (Doctoral Thesis). Universitat Rovira I Virgili, Tarragona, Spain. 